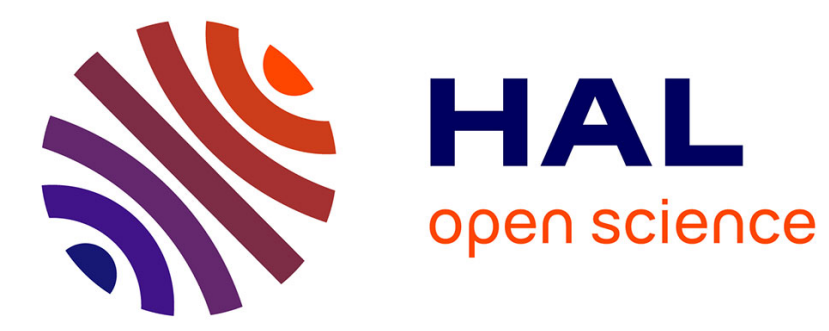

\title{
Discrete modeling of granular flow with thermal transfer: application to the discharge of silos
} V.D. Nguyen, C. Cogné, M. Guessasma, E. Bellenger, Jérôme Fortin

\section{To cite this version:}

V.D. Nguyen, C. Cogné, M. Guessasma, E. Bellenger, Jérôme Fortin. Discrete modeling of granular flow with thermal transfer: application to the discharge of silos. Applied Thermal Engineering, 2009, 29 (8-9), pp.1846. 10.1016/j.applthermaleng.2008.09.009 . hal-00558514

\section{HAL Id: hal-00558514 https://hal.science/hal-00558514}

Submitted on 22 Jan 2011

HAL is a multi-disciplinary open access archive for the deposit and dissemination of scientific research documents, whether they are published or not. The documents may come from teaching and research institutions in France or abroad, or from public or private research centers.
L'archive ouverte pluridisciplinaire $\mathbf{H A L}$, est destinée au dépôt et à la diffusion de documents scientifiques de niveau recherche, publiés ou non, émanant des établissements d'enseignement et de recherche français ou étrangers, des laboratoires publics ou privés. 


\section{Accepted Manuscript}

Discrete modeling of granular flow with thermal transfer: application to the discharge of silos

V.D. Nguyen, C. Cogné, M. Guessasma, E. Bellenger, J. Fortin

PII:

S1359-4311(08)00374-8

DOI:

10.1016/j.applthermaleng.2008.09.009

Reference:

ATE 2617

To appear in:

Applied Thermal Engineering

\section{APPLIED}

THERMAL

ENGINEERING

$\begin{array}{ll}\text { Received Date: } & \text { 15 January } 2008 \\ \text { Revised Date: } & \text { 15 July } 2008\end{array}$

Accepted Date: $\quad 10$ September 2008

Please cite this article as: V.D. Nguyen, C. Cogné, M. Guessasma, E. Bellenger, J. Fortin, Discrete modeling of granular flow with thermal transfer: application to the discharge of silos, Applied Thermal Engineering (2008), doi: 10.1016/j.applthermaleng.2008.09.009

This is a PDF file of an unedited manuscript that has been accepted for publication. As a service to our customers we are providing this early version of the manuscript. The manuscript will undergo copyediting, typesetting, and review of the resulting proof before it is published in its final form. Please note that during the production process errors may be discovered which could affect the content, and all legal disclaimers that apply to the journal pertain. 


\title{
Discrete modeling of granular flow with thermal transfer: application to the discharge of silos
}

\author{
V.D. Nguyen ${ }^{a}$, C. Cognéa,*, M. Guessasma ${ }^{a}$, E. Bellenger $^{a}$, \\ J. Fortin ${ }^{b}$ \\ ${ }^{a}$ Laboratoire des Technologies Innovantes, IUT de l'Aisne, 48 rue d'Ostende, \\ 02100 Saint Quentin, FRANCE \\ ${ }^{\mathrm{b}}$ Laboratoire des Technologies Innovantes, INSSET, 48 rue Raspail, 02100 Saint \\ Quentin, FRANCE
}

\section{Résumé}

Heat transfer in particulate beds has an important impact for many industrial processes as well as for the storage of particulate material. This study is aimed at modeling the granular flow and heat transfer between particles during the discharge of a silo. A numerical model based on the detection of contacts and the evolution of heat transfers in particle flow has been developed by using Discrete Element Method (DEM). Through this study, we model the heat flows generated by friction and its transfer by conductance. Influence of the friction coefficient and discharging velocity on the granular flow and heat transfer has been investigated through some numerical examples. This modeling enables to understand better the phenomena at the contact point between particles as well as the heat transfer for a great number of particles in motion from their intrinsic mechanical properties and contact conductance.

Key words: heat transfer, contact, friction, silo, DEM, particulate beds

\section{$1 \quad 1$ Introduction}

The published literature analysis has shown the importance of heat in granular media for industrial processes in applications as diversified as powder metallurgy, chemical reactors [1], food technology [2], thermal insulation [3]

*. Corresponding author.

Email address: claudia.cogne@u-picardie.fr (C. Cogné). 
or even simply storing particles in a silo after drying [4]. But few studies are interested in the understanding of thermal transfer during sliding contacts. However these complex phenomena with multi-physical characteristics are an essential element in the understanding of the discharging silo process. One of the difficulty is to be able to predict the forces of friction and the temperatures in the friction zone from the intrinsic properties of grains in contact.

From a thermal energy point of view, the sliding contact is the source of a heat generation, whose distribution between the different bodies is difficult to estimate [5]. Besides, the determination of the contact area, which plays an important role in the value of the transferred heat flow is also difficult to estimate. It depends on various parameters like porosity, particles state, the distribution of contact forces, the nature of each phase and the structure of media. Mechanical engineers are at the origin of the greatest number of works. Slavin et al. [6], Bahrami et al. [7] and Filali [8] have developed models to estimate the effective thermal conductivity of a particles packing, from the intrinsic properties of solids and fluids materials. These models enable to determine the apparent thermal conductivity evolution of a granular media depending on the mechanical forces applied to the particle bed. Vargas et al. [9] has studied more particularly the influence of contact pressure on the apparent conductivity of the bed with a small, but finite area of contact. All these models are considering the state surface of the spheres but only the heat transfers by contact are studied. Laguerre et al. [10] have presented a heat transfer model which took into account radiation phenomena in a packing so as to simulate the cooling of a fruit pile in a cold chamber. In all the above mentioned works, it is assumed that the study is realized in a static bed.

The first part of this work consists in using the Discrete Element Method (DEM) for the contact detection, the determination of contact forces and the kinematic parameters. A computational software MULTICOR, that can treat an important number of particles ( $10^{6}$ particles in $2 \mathrm{D}$ plane), has been developed to solve the mechanical equations. In a second time, the energy dissipation generating by friction and its transfer by contact have been studied and implemented in MULTICOR software. In the last part, through some experimental data and simulations, we underscore the phenomena of thermal and mechanical interaction during the discharge of the silo. We have investigated the influence of friction coefficient in the case of forced flow of granular media. Some phenomenon such as vault effect arising during the discharge of silo are observed and their influence on the heat dissipation into the granular media has been studied throughout numerical simulations. 


\section{Mechanical resolution by DEM}

46

The conventional DEM allows to model really deformable particles as well as complex shapes (from the ellipsoid to the polygon). Here, we have studied the simple case of non-deformable and non-penetrable particles in 2D plane with the computational programme MULTICOR, developed by Fortin et al [11]. The coordinates and the rotations of Euler are the configuration parameters $q$. The gyroscopic and centrifugal terms are equal to zero in 2D. The matrix of generalized mass $\underline{M}$ of the system doesn't depend on $q$ that is diagonal block. The mechanical equation can be written in the following form (Eq. 1):

$$
\underline{M} \ddot{q}=F_{\text {ext }}(q, \dot{q}, t)+R^{\alpha}
$$

where $F_{\text {ext }}$ represents the known external forces and $R^{\alpha}$ the unknown interior forces related to contact reactions with $\alpha$ the number of contacts for the considered particle.

In a system composed of $p$ heterogeneous particles, the critical parameter for the modelling time is the maximum number of interactions between particles. The more the interaction range is important the more we have to test the possible interactions between particles. MULTICOR uses the partitioning method coupled to a connectivity table [12]. This technique allows to reduce considerably the computational time. In that case, the computational time no longer increases like $O\left(p^{2}\right)$ but only like $O(p)$, which is almost optimal. For each couple of particles $\Omega_{i}$ and $\Omega_{j}$ which may enter in contact, is associated with a local reference whose axes are oriented according to the two unit vectors $n$ and $t$, respectively normal and tangential vectors in the contact plan (Fig. 1). The normal $n$ is directed from $\Omega_{j}$ to $\Omega_{i}$. The variables put in duality are $\dot{u}^{i j}$, the relative local velocity of $\Omega_{i}$ compared to $\Omega_{j}$, and the contact reaction $r^{i j}$ of $\Omega_{j}$ on $\Omega_{i}$. In the local base, they are written by:

$$
\dot{u}^{i j}=\dot{u}_{t}^{i j} t+\dot{u}_{n}^{i j} n, \quad r^{i j}=r_{t}^{i j} t+r_{n}^{i j} n,
$$

where $\dot{u}_{n}^{i j}$ is the normal separation velocity, $\dot{u}_{t}^{i j}$ the sliding velocity, $r_{n}^{i j}$ the contact pressure and $r_{t}^{i j}$ the adherence force.

The introduction of Coulomb's friction $\mu$ leads to a non linear problem which can't be solved by a linear programming method. Unlike the usual approach, the bipotential method leads to a single variational principle and an inequality [11]. By using Usawa's algorithm, we obtain a resolution algorithm of the constitutive law based on the predictive-corrective scheme expressed by Eq. 


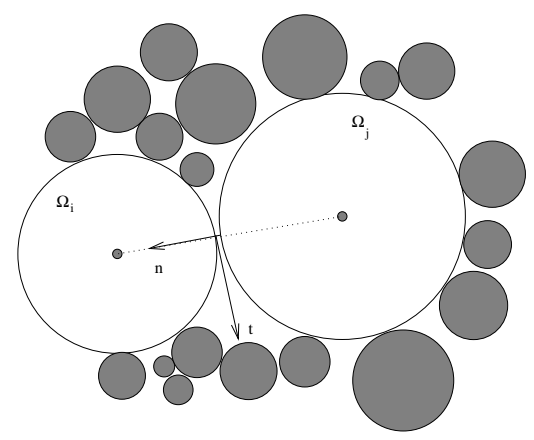

FIG. 1 -. A local referential.

$3:$

predictor : $\tau^{i j}=r^{i j}-\gamma\left[\dot{u}_{t}^{i j}+\left(\dot{u}_{n}^{i j}+\mu\left\|-\dot{u}_{t}^{i j}\right\|\right) . n\right]$,

where $\gamma$ is a numerical parameter and $\operatorname{proj}\left(\tau^{i j}, K_{\mu}\right)$ the projection of Coulomb's cone which leads, according to the value of $\tau^{i j}$, to one of these states: non contact, contact with adherence or sliding contact. Conventionally, at each time step, the contact forces in the system are determined repeatedly by the method of successive balances based on a Gauss-Seidel algorithm for the $2 D$ version. Each contact force is calculated by adopting temporary values over the other contacts. The convergence is obtained when the force confirms the unilateral contact law with dry friction. 
The calculation cycle is a time-stepped algorithm which requires the repetition of the following resolution scheme (Fig 2).

$$
\begin{aligned}
& t=t+\triangle t \\
& \text { Evaluation of the particle positions } q \\
& \text { Detection of the contact number } \alpha \text { in the system } \\
& \text { Evaluation of the particle velocity } \\
& \text { (without contact) } \\
& {[i=i+1 \quad \text { (iteration of solver bipotential) }} \\
& \alpha=\alpha+1 \quad \text { (contact loop) } \\
& \text { Evaluation of the contact reactions } r^{i j} \\
& \text { Indicator of error } \\
& \text { Evaluation of the velocity }
\end{aligned}
$$

FIG. 2 -. Algorithm for mechanical resolution.

\section{Heat transfer in granular media and thermal formulation}

In general, heat transfer in granular media with a stagnant interstitial fluid is assumed to occur because of the following physical phenomena:

- Thermal conduction through the particles and thermal conduction through the fluid between the neighboring particles. Furthermore, in a multi-contact system considered in this work, we must consider thermal conduction through the contact area between two particles $\Omega_{i}$ and $\Omega_{j}$. Contact conductance refers to the ability of transmitting heat across their mutual interface.

- Radiant heat transfer between the fluid within neighboring voids and radiant heat transfer between the surfaces of neighboring particles. For heat transfer by radiation, contact between surfaces is not required. Radiation is linked to the production of electromagnetic waves by a heat surface.

- For flowing fluid, heat transfer by interparticle convection can be considered if there is a difference of temperature between the particles and the fluid.

In frictional granular flow regimes, heat transfer occurs from the phenomenon presented above. In addition, it is necessary to consider the heat generated by friction between two particles $\Omega_{i}$ and $\Omega_{j}$. Indeed, the sliding contact is an 
important source of heat generation for dynamic granular problems considered in this work (Fig. 3a).

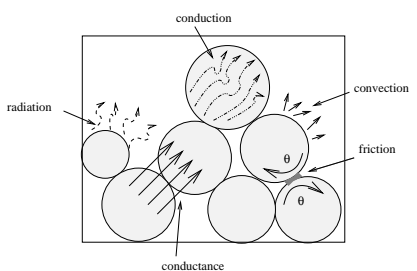

(a)

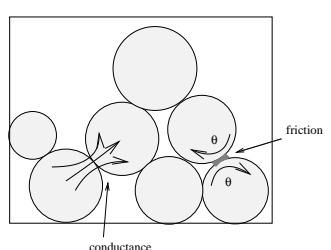

(b)

FIG. 3 -. (a) Heat transfer mechanisms in granular media (b) Heat transfer in MULTICOR software.

In this paper, we assume that conduction through the solid phase dominates the thermal conduction. This assumption is verified when:

$$
\frac{\lambda_{s} s}{\lambda_{f} a} \gg 1
$$

where $\lambda_{s}$ and $\lambda_{f}$ are respectively the conductivities of the particles and the fluid, $a$ and $s$ are respectively the radius of the particle and the contact area.

This expression is checked for high thermal conductivity of solid materials or for solid particles in a vacuum $\left(\lambda_{f} \rightarrow 0\right)$ [13]. Under these conditions, the heat transfer between two adjacent particles $\Omega_{i}$ and $\Omega_{j}$ is only controlled by the contact conductance. In this work, radiant and convective heat transfers are neglected. Therefore, we only consider heat transfer in granular flow by contact conductance and friction effect (Fig. 3b).

\subsection{Heat transfer by conductance}

Contact conductance is directly linked to the constriction of the heat flow lines in the contact point [2]. The thermal contact conductance is defined by the ratio of the heat flow across a contact interface and the magnitude of the discontinuity temperature at the interface (Eq. 5):

$$
\varphi_{i j}=H_{c}^{i j}\left(T_{j}-T_{i}\right)
$$

where $\varphi_{i j}$ is the heat flow transferred between the particles $\Omega_{i}$ and $\Omega_{j}, T_{j}-T_{i}$ the temperature difference between the mid-planes of the spheres and $H_{c}^{i j}$ the contact conductance between the particles $\Omega_{i}$ and $\Omega_{j}$ with $j$ varies from 1 to 
the contact number $\alpha$.

The coefficient $H_{c}^{i j}$ which is a function of the compression force, refers to the ability for two materials in contact to transfer heat through their mutual interface (Fig. 4). In our work, contact conductance between particles $\Omega_{i}$ and $\Omega_{j}$ is modeled using Hertz's theory (Eq. 6):

$$
H_{c}^{i j}=2 \lambda_{s} a_{H}=2 \lambda_{s}\left(\frac{3 r_{n}^{i j} a^{*}}{4 E^{*}}\right)^{1 / 3}
$$

where $r_{n}^{i j}$ is the normal force, $\lambda_{s}$ the thermal conductivity of the particle, $a_{H}$ hertzian contact radius and $a^{*}$ is the equivalent radius expressed by $\frac{1}{a^{*}}=$ $\frac{1}{a_{i}}+\frac{1}{a_{j}}, \frac{1}{E^{*}}=\frac{1-\nu_{i}^{2}}{E_{i}}+\frac{1-\nu_{j}^{2}}{E_{j}}$ the effective Young's modulus ( $E^{*}$ expresses an equivalent Young's modulus between the particles in contact) and $\nu$ Poisson's ratio.

The contact between two adjacent particles is assumed to be smooth and sliding. The contact conductance is calculated dynamically at each time step and for all contacts of a particle $\Omega_{i}$.

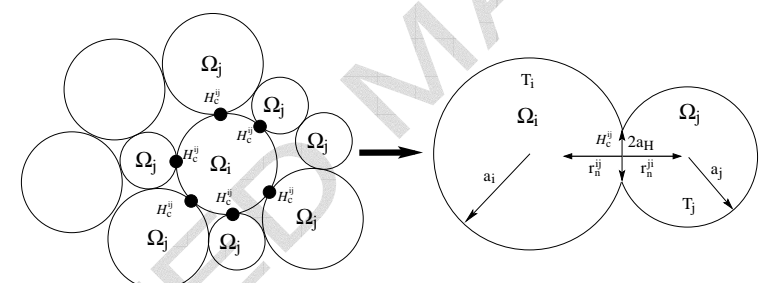

FIG. 4 -. Schematic representation of heat transfer by conductance.

We remind that the considered particles are non-deformable and non- penetrable. The using of Hertz's theory only enables us to compute the contact conductance coefficient $H_{c}^{i j}$. We assume that the particles remain rigid all the time.

\subsection{Heat generated by friction}

In this case, heat flow is generated by dissipation of energy during friction between particles. This assumption of mechanical energy dissipation is well known in thermomechanical field like braking [14] or high speed machining [15]. The deformation is neglected because the particles are assumed rigid. Friction is 
understood as continuous mechanical solicitations between two bodies. The heat energy generated by friction $E_{\mu_{i j}}$ at the frictional interface is:

$$
E_{\mu_{i j}}=\mu \dot{u}_{t}^{i j} r_{n}^{i j}
$$

The modeling of the energy generated by friction requires to share the heat between particles in sliding contact. Therefore, we define the partition coefficient of generated heat flow $\beta_{i j}$. This coefficient depends on different microscopic parameters like the thermal properties, the sliding velocity, heat generation parameters and the surface roughness if the contact is not perfect [16]. Research in this area has shown different equations to estimate this coefficient [17] [18]. In our study, this coefficient is obtained from the analytical solution of Varadi et al. [19] defined as the ratio of the conductivities:

$$
\beta_{i j}=\frac{\lambda_{s}^{i}}{\lambda_{s}^{i}+\lambda_{s}^{j}}
$$

We assume that the packed bed is made of only one material. The partition coefficient of generated heat flow $\beta_{i j}$ is then equal to $\frac{1}{2}$.

\subsection{Thermomechanical resolution}

Taking into account the various phenomena of heat generation mentioned above, the energy balance and the variation of temperature for a particle during a low time step $\triangle t$ can be written as follows (Eq. 9):

$$
m_{i} C_{P i} \frac{\triangle T_{i}}{\triangle t}=\sum_{j=1}^{\alpha}\left(H_{c}^{i j}\left(T_{j}-T_{i}\right)+\beta_{i j} E_{\mu_{i j}}\right)
$$

where $m_{i}$ and $C_{P i}$ are the mass and the heat capacity for $\Omega_{i}$ respectively, $\alpha$ the contact number.

The temperature evolution between two bodies in contact is governed by the equation (9), representing the balance of the heat energy. This equation is solved with a low time step $\left(\triangle t=10^{-3} s\right)$ to assume that the temperature of each particle changes slowly that thermal perturbations do not propagate further than its immediate neighbors during one time step. The second requirement is that the heat transfer resistance through a particle $\Omega_{i}$ (conduction) is significantly lower than the contact resistance between two particles $\Omega_{i}$ et 
$\Omega_{j}$, proved if:

$$
B i=\frac{H_{c}^{i j}}{\lambda_{s} a} \ll 1
$$

where $B i$ is equivalent to the Biot number. The equation used in order to compute the temperature $T_{i}$ at the time $(t+\triangle t)$ is given as follows:

$$
T_{i}^{t+\triangle t}=T_{i}^{t}+\frac{\triangle t}{m_{i} C_{P i}} \sum_{j=1}^{\alpha}\left(H_{c}^{i j}\left(T_{j}^{t}-T_{i}^{t}\right)+\beta_{i j} E_{\mu_{i j}}\right)
$$

The general algorithm implemented in MULTICOR software is represented in the following scheme (Fig. 5).

$[t=t+\triangle t$

Evaluation of the particle positions $q$

Detection of the contact number $\alpha$ in the system

Evaluation of the particle velocity

(without contact)

$[i=i+1 \quad$ (iterations of solver bipotential)

$[\alpha=\alpha+1 \quad$ (contact loop)

Evaluation the contact reaction $r^{i j}$

Indicator of error

Evaluation of $T_{i}^{t}, H_{c}^{i j}, E_{\mu_{i j}}$

Evaluation of the temperature $T_{i}^{t+\triangle t}$

Evaluation of the velocity

FIG. 5 -. Algorithm for thermal resolution.

The resolution of the heat problem requires to compute the contact detection, the determination of forces and the velocities of particles at each time step.

\section{Numerical simulation}

MULTICOR software can be used to simulate some industrial processes like sieving, crushing, filtration, etc. In the next sections, we have focused on the discharge of a silo both from a mechanical and in a thermal point of view. 


\subsection{Mechanical application}

In this part, the influence of the initial fill on the discharging process has been investigated. Only mechanical equations have been taken into account for the granular flow modeling in order to correlate MULTICOR predictions with experimental results developed in the works of Ketterhagen [4].The experiments have used bidisperse spheres with a mean diameter of $1.6 \mathrm{~mm}$ and $0.52 \mathrm{~mm}$. The dimensions of the silo and the properties of the particles are the same than the ones used experimentally by Ketterhagen [4].

The first study is the discharge of the silo with a well-mixed initial charge as shown in Fig. 6. The initial charge contains $10 \%$ of fine particles. Computationally, a well-mixed initial fill is relatively simple to obtain by assigning particle positions via a random number generator.

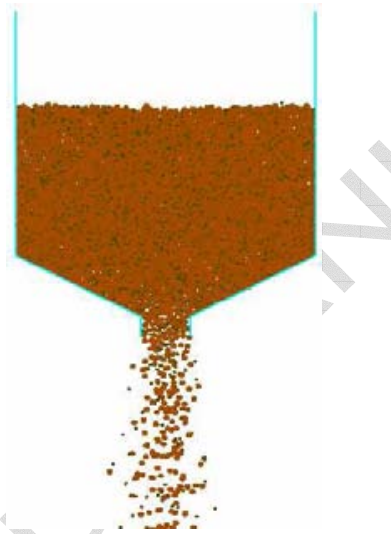

FIG. 6 -. Hopper discharge of a well-mixed initial fill.

The comparison of experimental results and computational data of discharged fine particles fraction is represented in Fig. 7. $M$ represents the cumulative mass discharge, $M_{T O T}$ the total mass initially charged in the silo and $x_{i}$ the fine mass fraction of discharged particles.

It should be noted that the discharge of the silo is homogenous but there is an over-prediction of the fine particles concentration by MULTICOR for $0.4<M / M_{T O T}<0.7$. The main reason may be due to variation in friction coefficient, particle shapes or homogeneity of the initial fill [4]. Moreover, the simulations have been carried out in two dimensions and do not reproduce perfectly the 3D experiments. Despite these differences, analysis of the weight fractions of the fine particles shows a quite good adequation between modeling and experimental data and allows us to provide a realistic prediction of granular flow during the discharge of silo. 


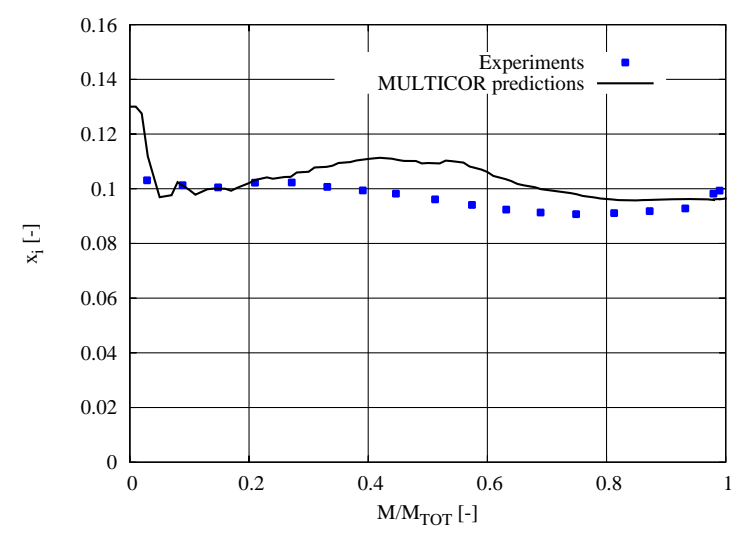

FIG. 7 -. Comparison of experimental and predicted mass fraction of fine particles during the discharge of a well-mixed initial fill.

The next example is a layered initial fill. The silo is filled with two horizontal layers, one for each of the particles diameter, fine over coarse particles (Fig. 9). The initial charge contains $50 \%$ of fine particles. Fig. 8 represents the evolution of fine particles $x_{i}$ versus the normalized discharged mass $M / M_{T O T}$.

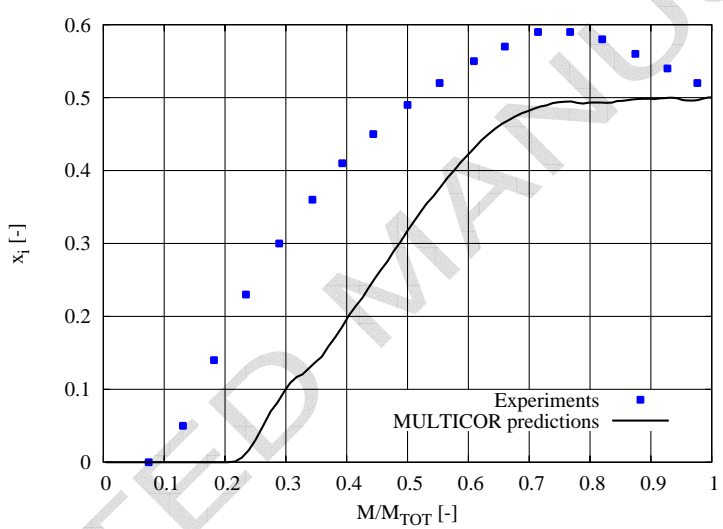

FIG. 8 -. Comparison of experimental and predicted mass fraction of fine particles during the discharge of a layered initial fill.

Unlike Fig. 7 that represents an homogenous discharge, three phases may be noted during the process (Fig. 8 and Fig. 9):

- phase 1: at first, only coarse particles are discharged (Fig. 9a).

- phase 2: as the flow proceeds, the centerline velocities increase and fine particles begin to discharge (Fig. $9 b$ ).

- phase 3: at the end of the discharge, the discharge is quite homogenous (Fig. $9 c)$.

As shown in Fig. 8, the experiments and MULTICOR predictions have the same shape. However, the MULTICOR software gives lower prediction with 


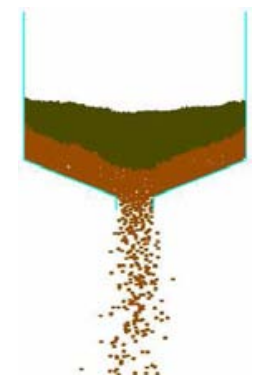

(a)

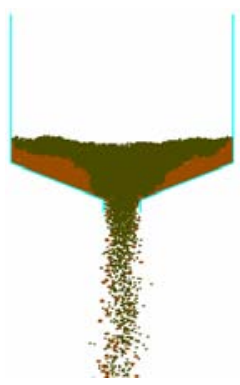

(b)

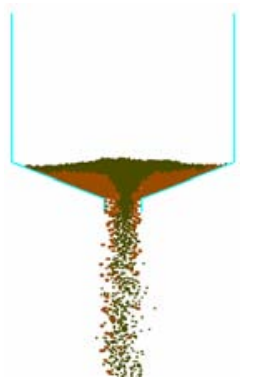

(c)

Fig. 9 -. The three phases of the hopper discharge filled in double layers.

respect to the experimental results. This difference may be due to the 2D plane modeling which cannot reproduce the same behavior as the experimental test.

After the mechanical validation of MULTICOR software for the discharge of silos, we propose to study heat transfer induced by vault effects during forced flow of granular media.

\subsection{Heat generation in forced flow of granular media}

In this section, MULTICOR software is expanded to include thermal phenomena so that its applications is not limited to isothermal system. Thermal equations are based on the normal force between two particles in contact (Eq. 6) so heat transfer are directly linked to the force chains. We have studied the influence of several parameters (friction coefficient, discharge forces) on the heat generation in granular forced flow. Through this parametric study, we have shown the influence of vault effects on the heat generation. Theses phenomena lead to problems for industrial processes such as hopper discharging [20] or grain conveying in pipes [21]. We precise that in theses works [20] and [21], the thermal aspects which can be observed for such industrial applications are not discussed.

In MULTICOR, we have assumed that the contact equations and the Hertz theory have been validated with experimental data in a static configuration in a previous work [22]. In the following parts 4.2.2 and 4.2.1, we have focused on the MULTICOR simulations of the forced silo discharging process to investigate the influence of physical phenomena on the temperature increase. The particles properties (steel particles) are summarized in Table 1 and the silo geometry is represented on Fig. 10. 


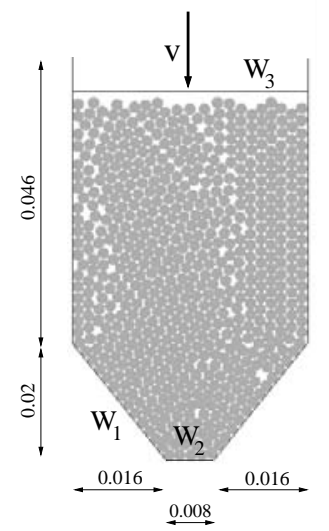

FIG. 10 -. Scheme of the silo.

After sedimentation in a closed silo, the wall W2 is opened allowing the beginning of the discharge. The discharging flow is controlled by the velocity $\mathrm{v}$ of the superior mobile wall W3. The initial temperature of the system is $T_{i n i}=25^{\circ} \mathrm{C}$. We have considered that the silo walls do not transfer heat with the exterior atmosphere. For each application, we have studied two parameters:

- the percent of the temperature increase on the wall W1 due to friction between particles: $100 \times\left(T(t)-T_{i n i}\right) / T_{\text {ini }}$,

- the normalized mass discharged $M(t) / M_{T O T}$,

where $T$ is the averaged temperature of the wall $\mathrm{W} 1, \mathrm{t}$ the time, $M$ is the mass discharged and $M_{T O T}$ the total mass of particles initially in the silo.

TAB. 1 -

\begin{tabular}{|ll|}
\hline Parameter & Value \\
\hline Density & $7800 \mathrm{~kg} \cdot \mathrm{m}^{-3}$ \\
Poisson ratio & 0.29 \\
Young's modulus & $193 \mathrm{GPa}$ \\
Particle radius & $10^{-3} \mathrm{~m}$ \\
Thermal conductivity & $15 \mathrm{~W} \cdot \mathrm{m}^{-1} \mathrm{~K}^{-1}$ \\
Number of particle & 600 \\
Heat capacity & $444 \mathrm{~J}_{\mathrm{kg}} \mathrm{kg}^{-1} \cdot \mathrm{K}^{-1}$ \\
\hline
\end{tabular}

Particles properties used in MULTICOR simulations. 


\subsubsection{Influence of the discharge velocity}

In this part, the friction coefficient is constant $(\mu=0.3)$ and the influence of discharging velocity is explored. Fig. 11 shows the impact of the velocity on the temperature increase inside the silo.

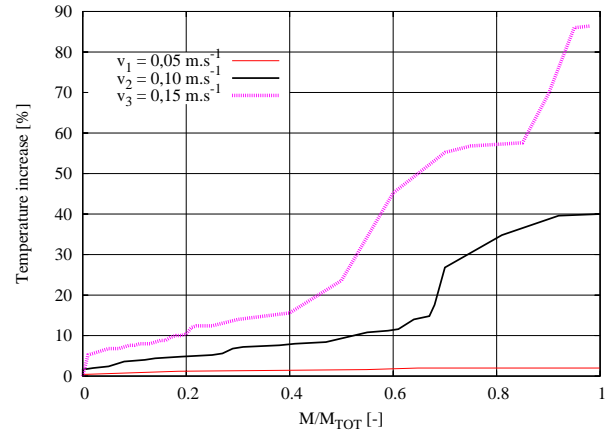

Fig. 11 -. Influence of the discharge velocity on the temperature increase.

A more striking result is seen in Fig. 12 when we examine the force chains after $0.1 \mathrm{~s}$ of discharge for three velocities $\left(5.10^{-2} \mathrm{~m} . \mathrm{s}^{-1}, 10^{-1} \mathrm{~m} . \mathrm{s}^{-1}\right.$ and $1.5 .10^{-1}$ $\left.m . s^{-1}\right)$. For an imposed velocity, the contact distribution is not homogenous, forces and also heat transfer follow preferred paths. And we note that the probability of finding contacts, directly linked to the conductance value, increases as the velocity increases.

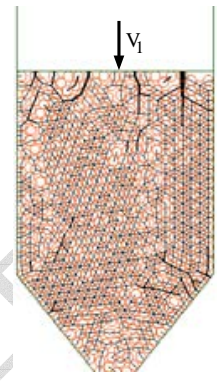

(a)

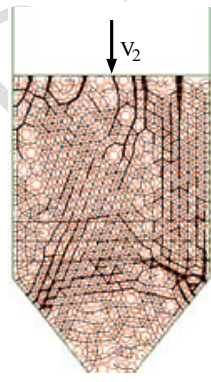

(b)

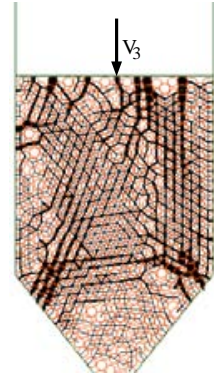

(c)

FIG. 12 -. Influence of the velocity on the force chains after $0.1 \mathrm{~s}$ of discharge; (a) $v_{1}=5 \cdot 10^{-2} \mathrm{~m} \cdot \mathrm{s}^{-1}$; (b) $v_{2}=10^{-1} \mathrm{~m} \cdot \mathrm{s}^{-1}$; (c) $v_{3}=1 \cdot 5 \cdot 10^{-1} \mathrm{~m} \cdot \mathrm{s}^{-1}$.

In this configuration, it is necessary to determine the better conditions of discharge. As represented in Fig. 13, increasing the discharge velocity means a lower discharge time, but in the same time it generates a larger increase of the wall temperature by friction at the end of the discharging process. So depending on the material properties of particles, the discharging flow should be optimized to control the heat generation. 


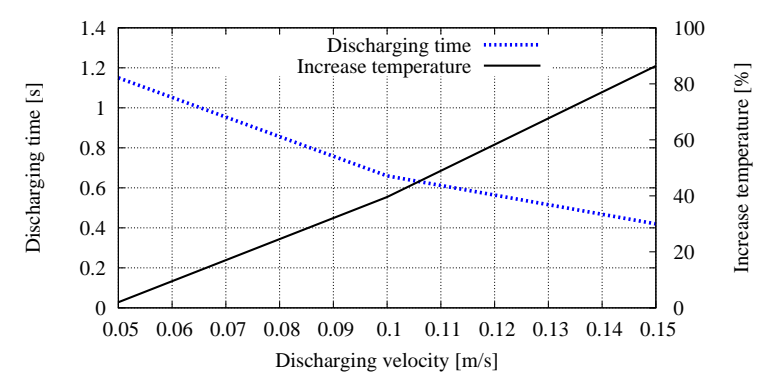

FIG. 13 -. Discharging time and increase temperature versus the discharging velocity

\subsubsection{Influence of the friction coefficient $\mu$}

Influence of the friction coefficient particle/particle and particle/wall on heat generation and temperature increase is investigated at constant discharge velocity $\left(\mathrm{v}=0.1 \mathrm{~m} . \mathrm{s}^{-1}\right)$. Fig. 14 represents the increase temperature versus the mass discharged for different friction coefficients. As expected, temperature increases significantly in case of large friction coefficients. But the temperature increase is not homogenous, steps can be noted in the heat generation especially for an important friction coefficient $(\mu=0.35)$ that could be explained with the analyze of the force chains. During the discharging flow for $0.4<M / M_{\text {TOT }}<0.7$, there is no increase of temperature. In this range, the forces chain represented in Fig. 15a shows low forces chains. On the contrary, for $M / M_{T O T}=0.7$, there is a gap in the temperature increase. In Fig. 15b, we note large force chains with vault effect at the bottom of the silo, generating heat by friction and temperature increase of the wall.

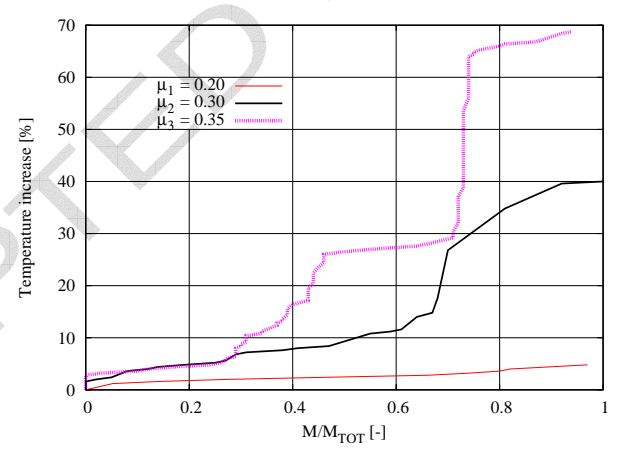

FIG. 14 -. Influence of the friction coefficient on the temperature increase.

\section{Conclusion}

The present work focuses on the extend of MULTICOR software, a computational code using discrete elements method, to incorporate heat transfer and heat generation from dissipation of mechanical energy. The results mentioned 


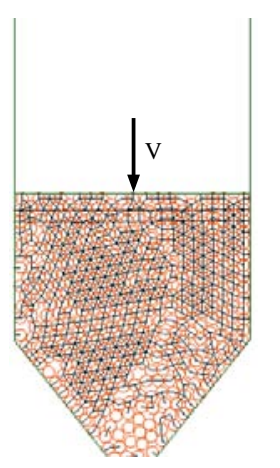

(a)

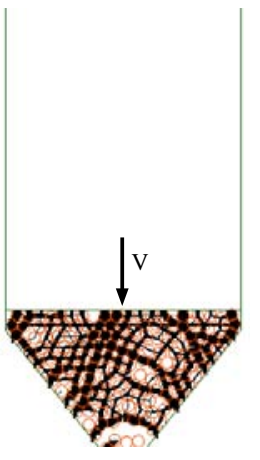

(b)

FIG. 15 -. Force chains; (a) low temperature increase; (b) large temperature increase.

here show a good adequation with experimental results from the literature, which allows us to validate our assumptions especially in the mechanical field. MULTICOR software also provides good qualitative agreements concerning the influence of the friction coefficient and the discharge velocity on the increase temperature in a silo.

The next step will consist in the incorporation of the other heat transfer phenomena like convection or radiation. Moreover, further studies will focus on the dynamic friction coefficient and its changes with the temperature and the wear in the contact area. An experimental campaign is also planned with our industrial partner INERIS, a French National Institute that has controlled risks for sustainable development, to validate our thermal assumptions in dynamic behavior.

\section{Acknowledgment}

The authors are grateful to Dominique Morel for her help in the article redaction.

\section{Références}

[1] B. Chaudhuri, F. J. Muzzio, and M.S. Tomassone. Modeling of heat transfer in granular flow in rotating vessels. Chemical Engineering Science, 61:6348-6360, 2006.

[2] O. Laguerre, S. Ben Amara, and D. Flick. Heat transfer between wall and packed bed crossed by low velocity airflow. Applied Thermal Engineering, 26:19511960, 2006. 
[3] S. Melka and J.J. Bézian. L'isolation thermique par les matériaux granulaire. Revue Générale de Thermique, 36:345-353, 1997.

[4] W.R. Ketterhagen, J.S. Curtis, C.R. Wassgren, A. Kong, P.J. Narayan, and B.C. Hancock. Granular segregation in discharging cylindrical hoppers: A discrete element and experimental study. Chemical Engineering Science, 62:6423-6439, 2007.

[5] P. Chantrenne and M. Raynaud. Study of a macroscopic sliding contact thermal model from microscopic models. International Journal of Thermal Science, 40:603-621, 2001.

[6] A.J. Slavin, V. Arcas, and C.A. Greenhalgh. Theoretical model for the thermal conductivity of a packed bed of solid spheroids in the presence of a static gas, with no adjustable parameters except at low pressure and temperature. International Journal of Heat and Mass Transfer, 45:4151-4161, 2002.

[7] M. Bahrami, M.M. Yovanovich, and J.R. Culham. Effective thermal conductivity of rough spherical packed beds. International Journal of Heat and Mass Transfer, 49:3691-3701, 2006.

[8] M. Filali. Conductivité thermique apparente des milieux granulaires soumis à des contraintes mécaniques: modélisation et mesure. $\mathrm{PhD}$ thesis, Institut National Polytechnique de Toulouse, 2006.

[9] W.L. Vargas-Escobar and J.J. McCarthy. Conductivity of granular media with stagnant intersitial fluids via thermal particle dynamics simulation. International Journal of Heat and Mass Transfer, 45:4847-485-, 2002.

[10] O. Laguerre, S. Ben Amara, and D. Flick. Transient heat and mass transfer by free convection in a packed bed of spheres: Comparison between two modellinng approaches and experimental results. Applied Thermal Engineering, Article in press, 2007.

[11] J. Fortin, O. Millet, and G. De Saxe. Numerical simulation of granular materials by an improved discrete element method. Journal of Computational and Applied Mathematics, 168:207-213, 2004.

[12] J. Fortin and P. Coorevits. Stratégie de calcul du pas optimal pour une modélisation éléments discrets. In Sixième Colloque National en Calcul des Structures, 2003.

[13] W.L. Vargas-Escobar and J.J. McCarthy. Stress effects on the conductivity of particulate beds. Chemical Engineering Science, 57:3119-3131, 2002.

[14] D. Majcherczak, P. Dufrenoy, and M. Naït. Third body influence on thermal friction contact problems: application to braking. ASME J. of Tribology, 127:8995, 2005.

[15] E. Guillot, B. Bougoura, B. Garnier, and L. Dubar. Experimental study of thermal sliding contact with friction: Application to high speed machining of metallic materials. In Proc. ESAFORM congress, 2007 (Zaragoza).

[16] V. Linck, A. Saulot, and L. Baillet. Consequence of contact local kinetics of sliding bodies on the surface temperatures generated. Tribology International, 39:1664-1673, 2006.

[17] B. Bougoura, J.M. Briot, and J.P. Bardon. Influence de la vitesse et de la charge sur la conductance thermique de transport entre les bagues d'un roulement à rouleaux. International Journal of Thermal Science, 40:622-637, 2000. 
[18] C.V. Madhusudana. Thermal conductance of cylindrical joints. International Journal of Heat and Mass Transfer, 42:1273-1287, 1999.

[19] K. Varadi, Z. Neder, and K. Friedrich. Evaluation of the real contact areas, pressure distributions and contact temperatures during sliding contact between real metal surfaces. Wear, 200:55-62, 1996.

[20] M. Guaita, A. Couto, and F. Ayuga. Numerical simulation of wall pressure during discharge of granular material from cylindrical silos with eccentric hoppers. Biosystems Engineering, 85(1):101-109, 2003.

[21] A.W. Roberts and M.J. Jones. Analysis of forced flow of granular materials in vertical pipes without and with air permeation. Particulate Science and Technology, 21:25-44, 2003.

[22] V. D. Nguyen, C. Cogné, J. Fortin, M. Guessasma, and E. Bellenger. Heat transfer modeling by discrete elements method. In 9th US National Congress on Computational Mechanics, San Francisco, 2007. 